\title{
PUSAT INFORMASI EKOSISTEM MANGROVE
}

\author{
Steven Susanto ${ }^{1)}$, Eduard Tjahjadi ${ }^{2)}$ \\ 1) Program Studi S1 Arsitektur, Fakultas Teknik, Universitas Tarumanagara, stevens.ta@stu.untar.ac.id \\ 2) Program Studi S1 Arsitektur, Fakultas Teknik, Universitas Tarumanagara, eduard.tjahjadi8@gmail.com
}

\begin{abstract}
Abstrak
Pertambahan populasi penduduk Jakarta menyebabkan kebutuhan akan ruang untuk sarana dan prasarana kota semakin meningkat. Cagar Alam Muara Angke pun dirambah sedikit demi sedikit hingga terjadi alih fungsi lahan yang masif. Akibatnya, dalam kurun waktu 30 tahun sebagian besar kawasan konservasi Muara Angke dengan luas lebih dari $1000 \mathrm{Ha}$ mengalami kerusakan sangat parah dan tidak dapat diselamatkan lagi. Besarnya kerusakan menyebabkan pemerintah menata ulang dan menetapkan kembali batas-batas kawasan Konservasi Cagar Alam Muara Angke. Perancangan ini diharapkan dapat membantu menyadarkan masyarakat metropolis tentang Ekologi dalam metropolis. Berkembangnya kota dapat bersamaan dengan perlindungan ekologi eksisting. Perencanaan pusat konservasi ini diharapkan menarik penjung dan menjadi sarana architourism dengan menyediakan ruang dan pengalaman ekologi. Pengunjung diharapkan akan merasakan ketertarikan pada pelestarian mangrove. Selain itu sarana ini juga akan menyediakan atraksi yang memberikan nilai serta kualitas wisata.
\end{abstract}

Kata kunci: arsitektur, ekologi , mangrove, metropolis.

\begin{abstract}
The increase in Jakarta's population causes the need for urban facilities and infrastructure to increase. The Muara Angke Nature Reserve was gradually added to the massive land conversion. As a result, within 30 years, most of the Muara Angke conservation area with an area of more than $1000 \mathrm{Ha}$ suffered severe damage and could not be saved anymore. the government restructured and re-established the boundaries of the Muara Angke Nature Reserve area. This design is expected to help make the metropolis aware of Ecology in the metropolis. The development of the city can coincide with the existing ecological protection. The conservation center planning is expected to attract people and become a means of Architourism by providing ecological space and experience. Visitors are expected to feel an interest in mangrove conservation. Besides this facility will also provide attractions that provide value and quality of tourism. In addition, space is also needed for commercial activities.
\end{abstract}

Keywords: architecture, architourism, ecology, mangrove, metropolis.

\section{PENDAHULUAN}

Dalam menjalani kehidupan manusia berada pada suatu ekosistem. Seluruh komponen ekosistem saling bergantung satu dengan lainnya. Komponen biotik terdiri dari produsen, konsumen dan pengurai, sedangkan komponen abiotik terdiri dari cahaya, udara, air, tanah, suhu, dan mineral. Seluruh komponen ini sangat diperlukan dalam kelangsungan kehidupan manusia.

Tanpa disadari, perkembangan peradaban manusia telah mengorbankan keseimbangan ekosistem. Pertumbuhan metropolis diperlukan pula untuk mendukung manusia yang hidup didalamnya. Tanpa disadari ekosistem awal dari kota metropolis dilupakan dan mengakibatkan kerusakan. Kualitas kehidupan manusia pun tanpa sadar terus menurun dengan dalam lingkungan metropolis.

Kerusakan ekologi yang telah terjadi diharapkan dapat diatasi dengan berbagai jenis usaha pelestarian alam. Dalam kasus kerusakan hutan mangrove di Jakarta, telah dilakukan penanaman ribuan bibit baru di sekitar pesisir Jakarta. Pentingnya pelestarian dapat terus 
berlangsung dengan kesadaran masyarakat.

Perancangan ini diharapkan dapat membantu menyadarkan masyarakat metropolis tentang konteks ekologi dalam kota metropolis; berkembangnya kota dapat bersamaan dengan perlindungan ekologi eksisting.

Tujuan perencanaan ini diharapkan menciptakan sebuah karya arsitektur yang dapat menjadi bagian dari metropolis, namun secara bersamaan melindungi ekosistem mangrove serta membantu ekonomi dari penduduk sekitar. Ruang Informasi Ekosistem Mangrove ini Diharapkan menjadi infrastruktur baru dalam memdukung pelestarian alam. Pengunjung yang datang dapat mempelajari pentingnya pelestarian ekosistem tersebut. Melalui memori yang tercipta dari ruang tersebut diharapkan generasi mendatang akan lebih menghargai dan melindungi ekosistem yang telah ada.

Perencanaan pusat konservasi ini diharapkan menarik pengunjung dan menjadi sarana architourism dengan menyediakan ruang dan pengalaman ekologi. Pengunjung diharapkan akan merasakan ketertarikan pada pelestarian mangrove. Selain itu sarana ini juga akan menyediakan atraksi yang memberikan nilai serta kualitas tourism. Selain itu juga diperlukan ruang ruang untuk kegiatan komersial.

\section{METODE}

Metode yang digunakan yaitu metode deskriptif dengan mengumpulkan dan menguraikan data primer dan sekunder yang telah didapatkan. Data primer didapat dengan melakukan survey lapangan dengan pengamatan langsung dan membuat dokumentasi, sedangkan data sekunder didapat dari data statistik dan kepustakaan yang berkaitan dengan aspek wisata

\section{DISKUSI DAN HASIL}

Total luas hutan mangrove di Indonesia adalah 25\% dari keseluruhan hutan mangrove dunia yang tersebar di 90 ribu kilometer garis pantai. Namun laju kerusakan hutan mangrove di Indonesia merupakan yang tercepat dan terbesar di dunia. Semua pihak, termasuk perusahaan swasta, masyarakat, akademisi, dan lembaga swadaya masyarakat ikut terlibat memulihkan kawasan hutan mangrove. Kerusakan hutan mangrove bisa menjadi penyebab terjadinya bencana alam, seperti abrasi dan erosi, yang menggerus wilayah daratan.

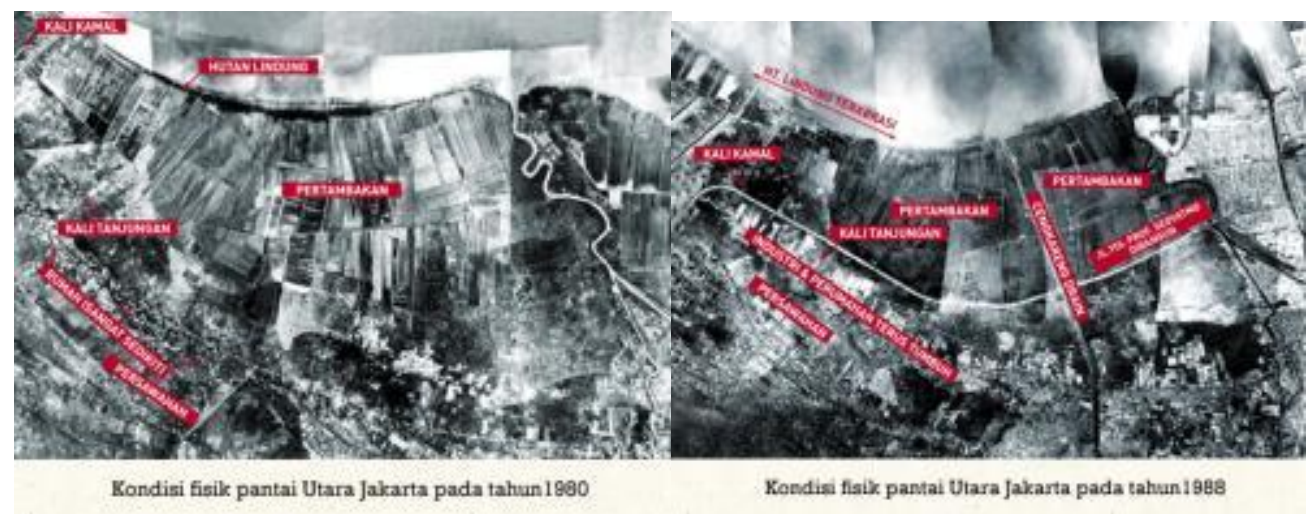

Gambar 1. Kondisi Fisik Pantai Utara Jakarta Kurun Waktu 1980-1988 Sumber: Kodoatie, 2005 


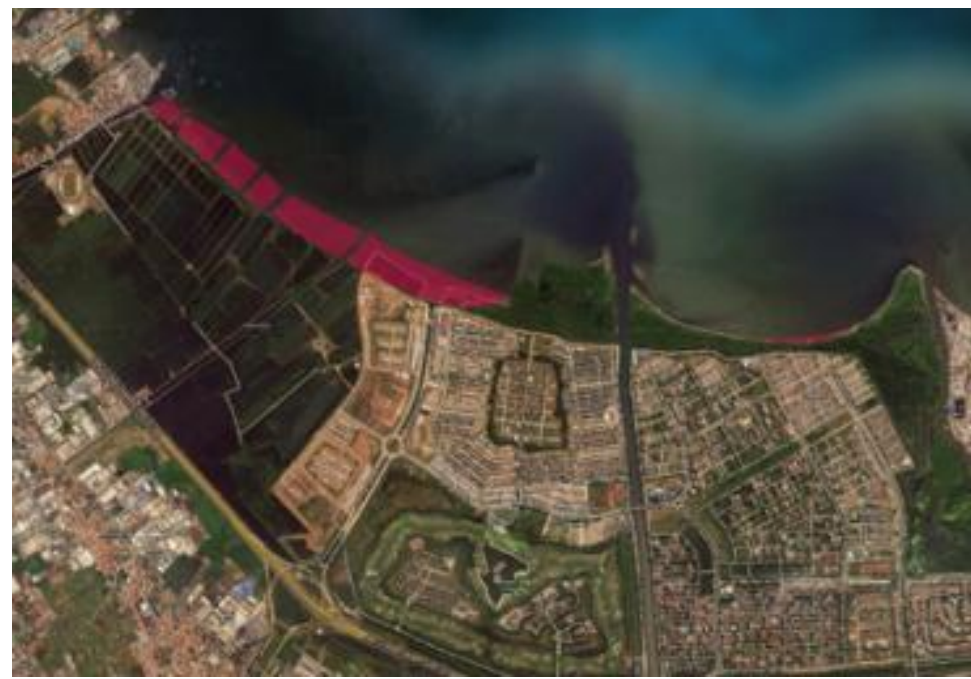

Gambar 2. Kondisi Fisik Pantai Utara Jakarta

Sumber: Google Earth

Kerusakan ini dipicu dari kurangnya kesadaran masyarakat metropolis terhadap pentingnya keberadaan ekosistem mangrove. Wisata ekologi mangrove yang terletak pada kawasan tersebut telah banyak berkontribusi dalam menyadarkan pengunjung akan pentingnya ekologi mangrove. Meskipun memiliki peran sangat penting, namun fasilitas pendukung wisata ini masih bisa dikatakan minim. Dalam skala nasional dan mancanegara pengunjung seringkali datang dalam jumlah besar dengan menggunakan bus. Fasilitas ini cukup sulit dijangkau dengan menggunakan kendaraan besar karena jalan akses masuk hanya dengan lebar jalan hanya $6 \mathrm{~m}$. Selain itu dari jalan arteri juga tidak memiliki signage yang menunjukan bahwa jalan tersebut menuju wisata mangrove. Meskipun sudah cukup terkenal, diperlukan integrasi yang jelas agar wisata ini dapat didukung perkembangan wisata rekreasi yang sudah berkembang di sekitarnya.

\section{Informasi Lahan}

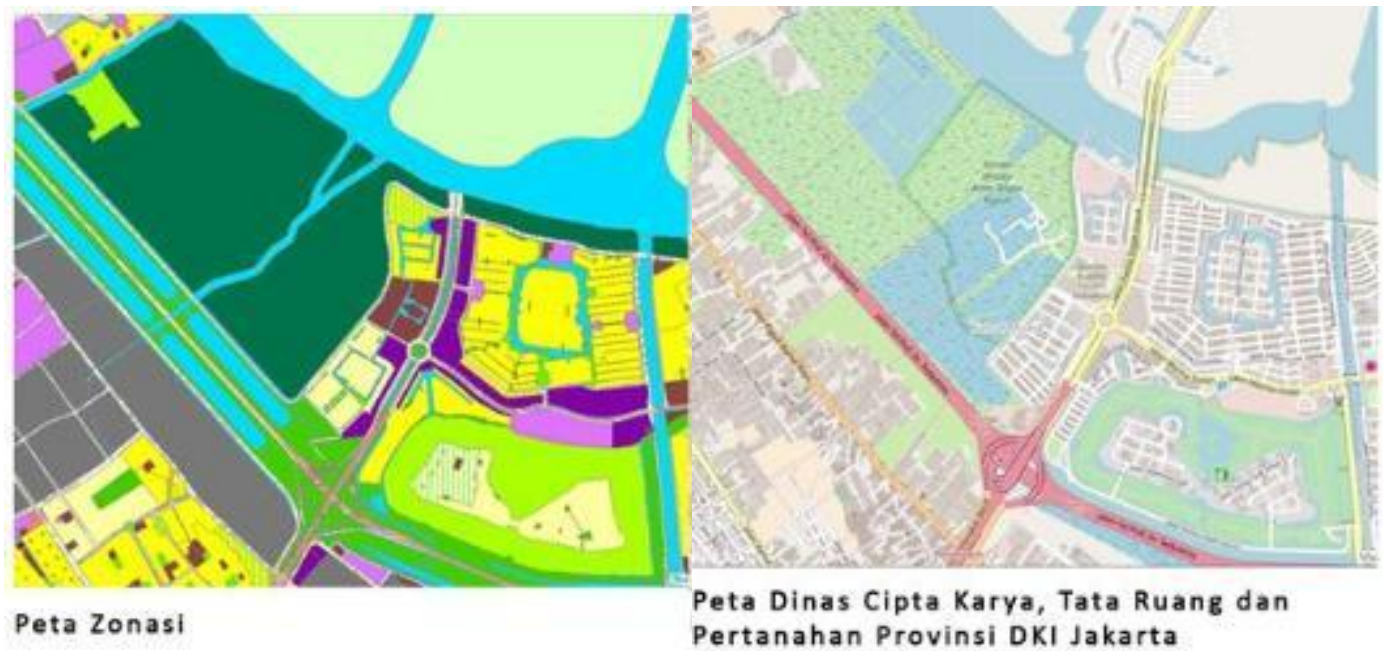

Gambar 3. Informasi Lahan

Sumber: Peta Zonasi, RDTR dan Google Maps 
Vol. 1 , No. 1

\section{HISTORIC TIMELINE}
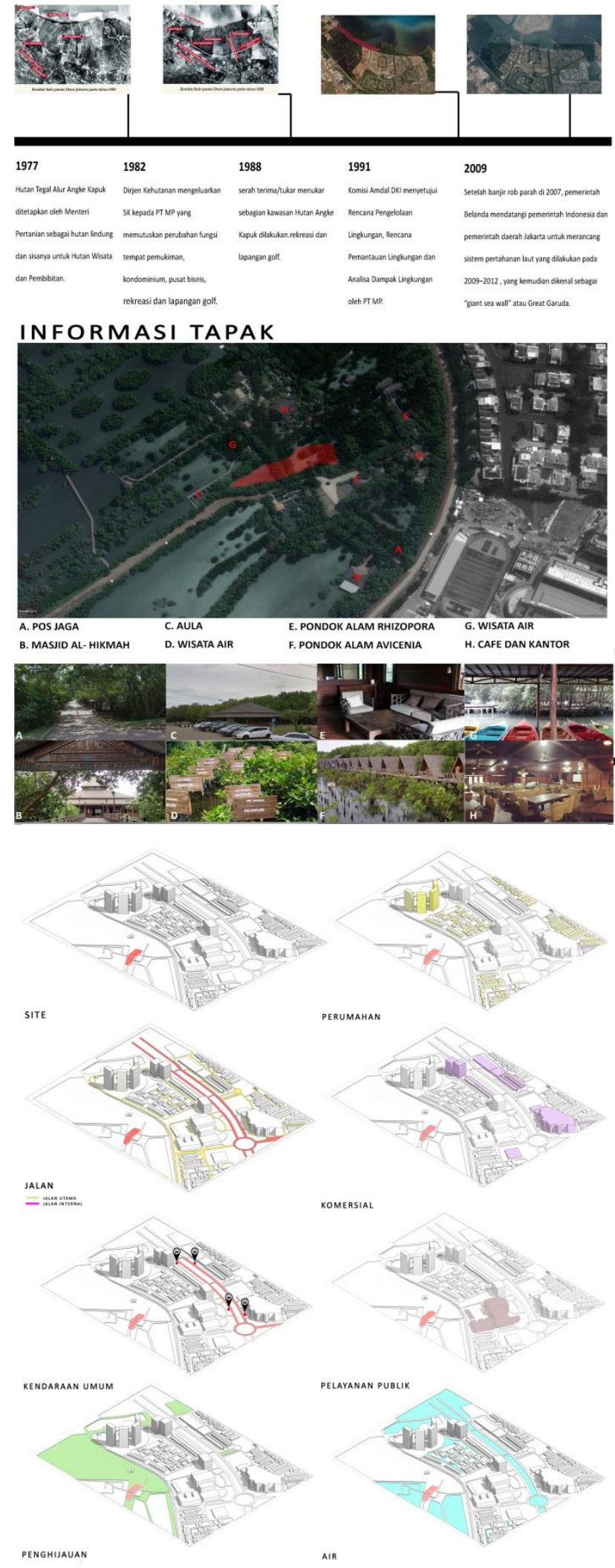

Gambar 3. Diagram Informasi Analisis Tapak Sumber: Olahan penulis, 2018 


\section{Hasil Rancangan}

Kurangnya kesadaran terhadap pentingnya hutan mangrove dan kurangnya integrasi kawasan terhadap ekowisata mangrove menjadi permasalahan utama. Dalam kasus ini diperlukan perbaikan dan perencanaan konsep tourism architecture dan architectural tourism dalam melakukan pendekatan terhadap masalah ini.

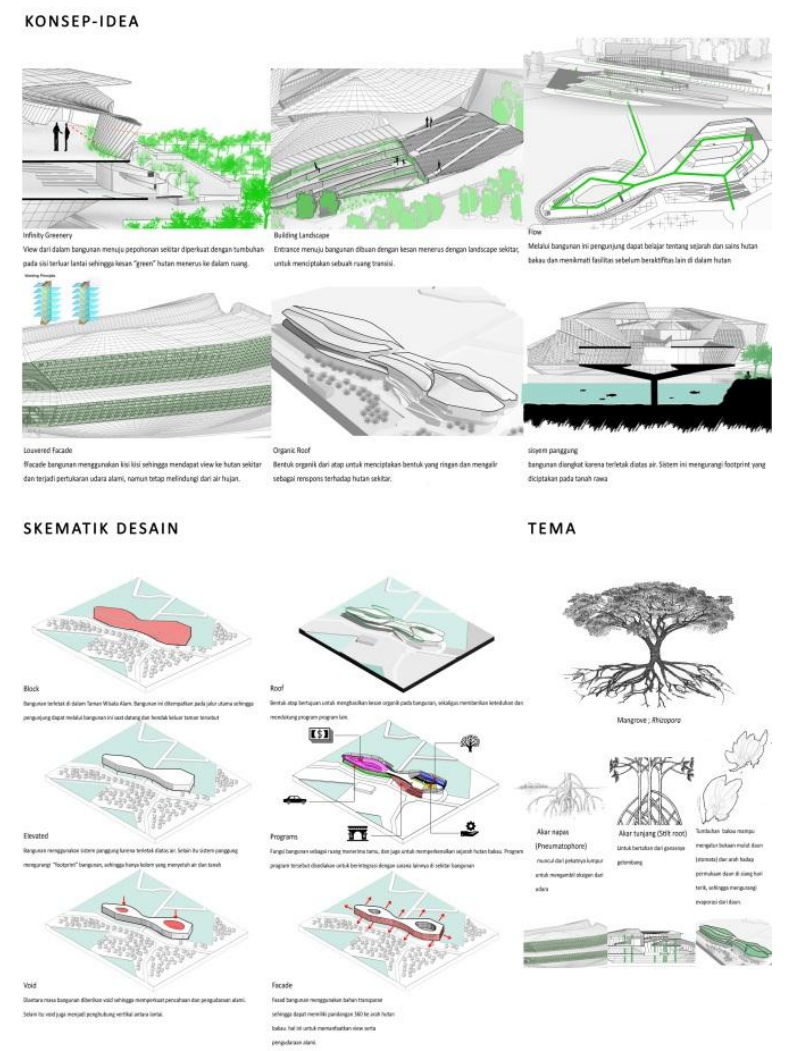

Gambar 4. Tema, Konsep, dan Skematik Proses Gubahan Massa Sumber: Olahan penulis, 2018

Melalui pendekatan architourism seperti halnya Bilbao Guggenheim museum, bangunan tersebut tidak hanya berdiri sendiri melainkan dengan dukungan infrastruktur yang baik. Dalam hal ini perlu diciptakan fasilitas-fasilitas pendukung agar memberikan pengalaman yang lebih baik. Sekarang ini wisata tersebut sudah sangat terkenal dengan keindahan alamnya dan potensi hutan kota. Namun, infratruktur kawasan kurang mendukung sehingga mengurangi potensi dari wisata tersebut. Architourism melalui terciptanya sebuah sarana dan ruang baru serta fasilitas pendukung lainnya diharapkan dapat menghidupkan wisata ekologi mangrove.

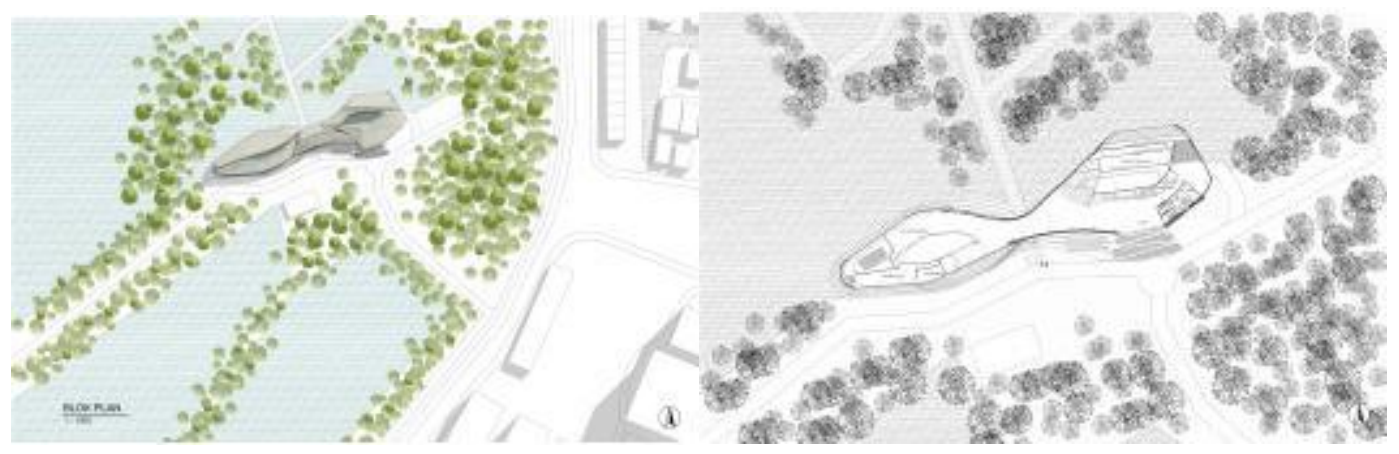

Gambar 5. Pengolahan Tapak

Sumber: Olahan penulis, 2018 
Dengan melihat data dan analisa dari sekitar tapak, program yang cocok diaplikasikan adalah sebuah fasilitas pusat konservasi yang merupakan sebuah pusat dari ekowisata mangrove. Ini bertujuan untuk mengangkat potensi wisata yang belum sepenuhnya tercapai di kawasan hutan mangrove dan PIK sebagai architourism. Untuk mendatangkan wisatawan lokal ataupun mancanegara, proyek ini akan menjadi salah satu tujuan utama wisatawan dalam berkunjung ke area PIK. Bangunan ini akan memiliki 3 bagian yaitu 1) pusat informasi wisata mangrove, 2) ruang pamer untuk sejarah dan karya serta hal lain yang berhubungan dengan ekowisata mangrove dan 3) lantai observasi dan sarana komersial. Ketiga bagian ini melambangkan fungsi bangunan ini dalam mendukung menciptakan sebuah architourism baru; 1) dengan menyediakan infrastruktur untuk wisata mangrove yang sudah ada, 2) dengan memperkenalkan dan mengintegrasikan wisata dengan lingkungannya dan 3) menciptakan kemungkinan untuk ekonomi.

Dalam konsep architectural tourism oleh Jan Spect, terdapat pembahasan Contemporary Architecture and the Destination Image. Dalam bab ini dibahas pentingnya hubungan antara fotografi dan arsitektur. Hal ini dikarenakan berkembangnya suatu objek wisata adalah karena karya fotografi yang memikat perhatian wisatawan. Dengan demikian program berupa galeri tersebut diharapkan dapat menampilkan karya karya pengunjung yang datang. Keindahan lokasi ini diharapkan akan tercapai potensinya dengan kehadiran galeri tersebut.

Dalam artikel The Bilbao effect ditekankan pentingnya infrastruktur yang mendukung wisata tersebut Bilbao Gugenheim memiliki kesuksesan yang didukung oleh berbagai macam fasilitas yang direncanan untuk mendukung. Tanpa fasilitas pendukung tentu sulit untuk mengulang bilbao effect tersebut. Hal ini tercermin dengan kota-kota lain di Spanyol yang bangkrut saat krisis melanda dikarenakan mega project yang mereka kerjakan, namun tidak mendatangkan efek sebesar Bilbao. Dalam proyek ini kehadiran galeri sebagai pusat informasi berfungsi untuk menerima tamu yang datang. Ruang ini juga sekaligus menjadi ruang transisi antara hutan mangrove dan dunia metropolis diluar. Dalam ruang tersebuat akan disediakan information center yang akan membantu pengunjung yang datang. Informasi yang diberikan adalah terkait hal yang bias dinikmati dalam wisata tersebut
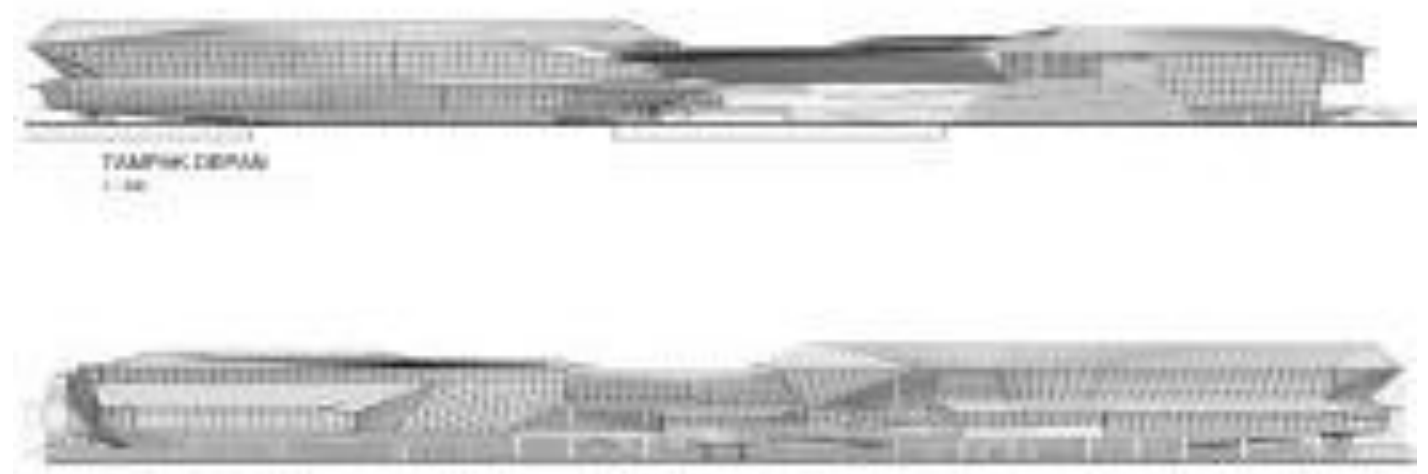

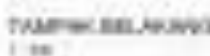

Gambar 6. Gambar Tampak

Sumber: Olahan penulis, 2018 


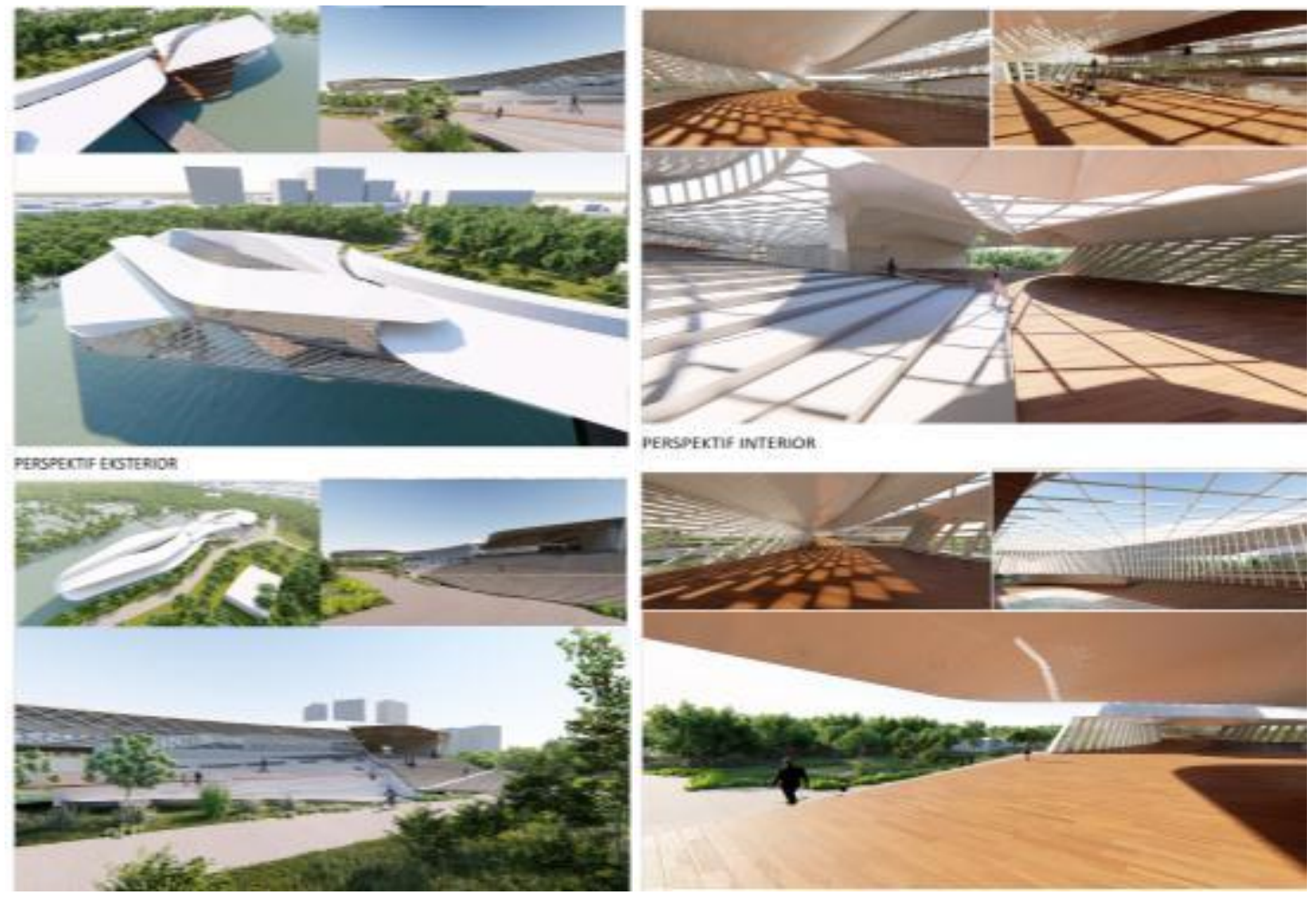

Gambar 7. Gambar Perspektif Eksterior dan Interior Sumber: Olahan penulis, 2018

\section{KESIMPULAN DAN SARAN}

Dalam perancangan architourism diperlukan unsur komersial sehingga bangunan tersebut dapat bertahan dalam derasnya kapitalisasi metropolis. Hal ini melahirkan sebuah program komersial dalam bangunan ini. Lantai atas bangunan akan memiliki view yang baik ke arah hutan mangrove. Dengan demikian ruang tersebut dapat dimanfaat untuk menciptakan program viewing deck dan restoran dengan view hutan bakau. Tujuan utama dari program program tersebut adalah menciptakan ruang ruang yang akan menjadi 'jembatan' antara dunia metropolis dan dunia ekowisata mangrove. Ruang yang tercipta diharapkan menjadi 'transitional space' atau ruang diantara yang akan mengantar pengunjung masuk dan keluar wisata tersebut, sekaligus melindungi ekosistem itu sendiri.

Dalam perencanaan ini diharapkan murid dapat menciptakan sebuah karya arsitektural yang berkontribusi pada perkembangan metropolis dengan membangun turisme. Bentukan Arsitektural yang dirancang diharapkan akan mampu menjadi destinasi dan atraksi wisata di tengan ruang metropolis.

\section{UCAPAN TERIMA KASIH}

Penulis menyampaikan terima kasih kepada Dosen Pembimbing, Narasumber, dan semua pihak yang telah berkontribusi dalam pembuatan makalah ini.

\section{REFERENSI}

Specht, Jan. (2014). Architectural Tourism: Building for Urban Travel Destinations. Gabler Verlag

Smith, R.; Smith, R. M. (2000). Ecology and Field Biology. (6th ed.). Prentice Hall.

Begon, M.; Townsend, C. R., Harper, J. L. (2006). Ecology: From individuals to ecosystems. (4th ed.). Blackwell.

Herre, E. A.; Knowlton, N.; Mueller, U. G.; Rehner, S. A. (1999). "The evolution of mutualisms: Exploring the paths between conflict and cooperation.". Trends in Ecology and Evolution 
14: 49-53.

"What is Ecotourism? | The International Ecotourism Society". www.ecotourism.org. 2016-1117

Stabler, M.J. (eds.) (1997, page 45) Tourism and Sustainability: Principles to Practice. CAB International: Wallingford.

Wight, P.A. (1993). Ecotourism: Ethics or Eco-sell. Journal of Travel Research. pp. 31(3):3-9. 